Objectives: To investigate the longitudinal associations between features on magnetic resonance (MR) imaging and joint tenderness in patients with primary hand $O A$ over two years.

Methods: Eighty-five consecutively included patients $(81.2 \%$ women, mean age 59.2 years) with primary hand OA ( $89.4 \%$ fulfilling ACR classification criteria) from a rheumatology outpatient clinic received contrast-enhanced MR imaging (1.5T) and physical examination of the right hand interphalangeal joints of digits $2-5$ at baseline and at follow-up two years later. MR images were scored paired in unknown time order, following the Hand OA MRI scoring system: synovitis, BMLs, and osteophytes on a 0-3 scale (higher score reflects worse condition), with halfpoint increments allowed for synovitis and BMLs delta-scores. Joint tenderness upon palpation was assessed by trained research nurses on a $0-3$ ordinal scale. We tested the associations between decreased MR features and decreased tenderness by calculating odds ratios on joint level $(n=680)$, using generalised estimating equations to account for the within patient effects. Additional adjustments were made for change in MR-defined osteophytes, synovitis, and BMLs, when appropriate. Similarly, we tested the associations between increased MR features and increased tenderness, and we explored interactions between the different MR features by stratifying for one another.

Results: Decrease in synovitis was seen in 90 joints and decrease in BMLs in 56, however when restricted to the 116 joints with baseline tenderness, at follow-up: 76 had reduced tenderness, 21 decreased synovitis, and 13 decreased BMLs. A decrease in synovitis, but not in BMLs, was associated with attenuated tenderness (table 1). Of 678 joints without maximum baseline tenderness, at follow-up: 115 had increased tenderness, 132 increased synovitis, 96 increased BMLs, and 44 increased osteophytes. An increase in synovitis, osteophytes, and, to a lesser extent, BMLs, was associated with increased tenderness (table 2). Through stratification it became apparent that BMLs were merely an effect modifier of the synovitis-tenderness association.

Table 1 The associations between decreased MRI features and decreased joint tenderness (in joints with tenderness and MRI feature present at baseline)

\begin{tabular}{|c|c|c|c|}
\hline & $\begin{array}{l}\text { N/total (\%) joints with } \\
\text { decreased tenderness }\end{array}$ & $\begin{array}{l}\text { Adjusted analyses } \\
\text { OR }(95 \% \mathrm{Cl})\end{array}$ & $\begin{array}{l}\text { Adjusted analyses }^{6} \\
\text { OR }(95 \% \mathrm{Cl})\end{array}$ \\
\hline \multicolumn{4}{|l|}{ Synovitis } \\
\hline Stable/increase & $30 / 58(51.7)$ & 1.0 (reference) & 1.0 (reference) \\
\hline Decrease & $17 / 21(81.0)$ & $3.99(0.95-16.76)$ & $5.88(1.12-30.95)$ \\
\hline \multicolumn{4}{|l|}{ Bone marrow lesions } \\
\hline Stable/increase & $23 / 39(59.0)$ & 1.0 (reference) & n.a. \\
\hline Decrease (20.5) & $6 / 13(46.2)$ & $0.39(0.10-1.50)$ & n.a. \\
\hline Decrease (z1) & $5 / 11(45.5)$ & $0.53(0.14-1.95)$ & n.a. \\
\hline
\end{tabular}

Table 2 The associations between increased MRI features and increased joint tenderness (in joints without maximum tenderness at baseline)

\begin{tabular}{|c|c|c|c|}
\hline & $\begin{array}{l}\mathrm{N} / \text { total (\%) joints with } \\
\text { increased tenderness }\end{array}$ & $\begin{array}{l}\text { Adjusted analyses } \\
\text { OR }(95 \% \mathrm{Cl})\end{array}$ & $\begin{array}{l}\text { Adjusted analyses } \\
\text { OR }(95 \% \mathrm{Cl})\end{array}$ \\
\hline \multicolumn{4}{|l|}{ Synovitis } \\
\hline Stable /decrease & $78 / 536(14.6)$ & 1.0 (reference) & 1.0 (reference) \\
\hline Increase & $36 / 132(27.3)$ & $1.80(1.11-2.91)$ & $1.81(1.11-2.94)$ \\
\hline \multicolumn{4}{|l|}{ Bone marrow lesions } \\
\hline Stable /decrease & $94 / 569(16.5)$ & 1.0 (reference) & 1.0 (reference) \\
\hline Increase (20.5) & $17 / 96(17.7)$ & $1.40(0.99-1.97)$ & $1.14(0.81-1.60)$ \\
\hline Increase (Z1) & $11 / 51(21.6)$ & $1.66(0.99-2.78)$ & $1.33(0.82-2.17)$ \\
\hline \multicolumn{4}{|l|}{ Osteophytes } \\
\hline Stable & 102/632 (16.1) & 1.0 (reference) & 1.0 (reference) \\
\hline Increase & $13 / 44(29.5)$ & $2.58(1.53-4.38)$ & $2.75(1.59-4.77)$ \\
\hline
\end{tabular}

Conclusions: In hand OA, a decrease in MR-defined synovitis is associated with a decrease in joint tenderness. Furthermore, an increase in synovitis or osteophytes is associated with increased tenderness, which is further augmented by co-occurrence of BMLs. These findings support targeting synovitis in hand OA.

Disclosure of Interest: None declared

DOI: 10.1136/annrheumdis-2018-eular.2327

\section{FRI0548 ASSOCIATION OF OMERACT CORE DOMAINS OF PAIN AND FUNCTION WITH PATIENT SATISFACTION AFTER TOTAL JOINT REPLACEMENT}

S.M. Goodman ${ }^{1,2}$, B. Mehta ${ }^{1,2}$, L.A. Mandl ${ }^{1,2}$, J. Szymonifka ${ }^{3}$, M.P. Figgie ${ }^{4,5}$, I. Navarro-Millan ${ }^{1,2}$, M. Bostrom ${ }^{4,5}$, D.E. Padgett ${ }^{4,5}$, A.S. McLawhorn ${ }^{4,5}$, S. Lyman $^{3}$, J. Singh $6 .{ }^{1}$ Rheumatology, Hospital for Special Surgery, ${ }^{2}$ Rheumatology, Weill Cornell Medicine; ${ }^{3}$ Biostatistics; ${ }^{4}$ Orthopaedics, Hospital for Special Surgery; ${ }^{5}$ Orthopaedics, Weill Cornell Medicine, New York; ${ }^{6}$ Rheumatology, University of Alabama, Birmingham, USA

Background: Up to $20 \%$ of Total Joint Replacement (TJR) patients are dissatisfied, but this is difficult to study as it is challenging to pool data due to the lack of unified core outcome measures. The OMERACT TJR Special Interest Group has recently endorsed a core domain set that include pain and function, and now seeks validation prior to development of a TJR trial core measurement set.

Objectives: To assess the association of pain relief and improved function with patient satisfaction 2 years after TJR.

Methods: We identified all patients undergoing total hip (THR) and knee (TKR) replacement in a hospital-based registry from 2007-2011, and evaluated those with 2 year satisfaction scores. Pain and function were measured using the Knee and Hip injury and Osteoarthritis Outcome Score (KOOS, HOOS) and satisfaction was measured using 5 primary questions, each rated on a Likert scale. Each question was weighted equally and a satisfaction summary score was calculated (range 0-100, higher scores corresponding to greater satisfaction). Expectations were measured using the validated HSS Expectations survey. Correlation was analysed with Spearman coefficients, and scores were compared by quartiles using the Kruskal-Wallis test.

Results: We included 4796 primary unilateral TKR and 4801 THR. $78 \%$ of TKR and $90.7 \%$ of THR were very satisfied with pain relief, and $6.5 \%$ of TKR and $2.5 \%$ of THR were somewhat or very dissatisfied (table 1). Satisfaction correlated moderately with pain (TKR $\rho=0.61$, THR $\rho=0.47$ ) and function (TKR $\rho=0.65$, THR $\rho=0.51$ ) at 2 years; there was no correlation with baseline expectations. When comparing satisfaction by pain, function and expectation quartiles, there were statistically significant differences (table 2); those with the best scores and greatest change in pain and function were the most satisfied.

Abstract FRI0548 - Table 1. Satisfaction Questions and Distribution



Abstract FRI0548 - Table 2. Association between outcomes and Satisfaction

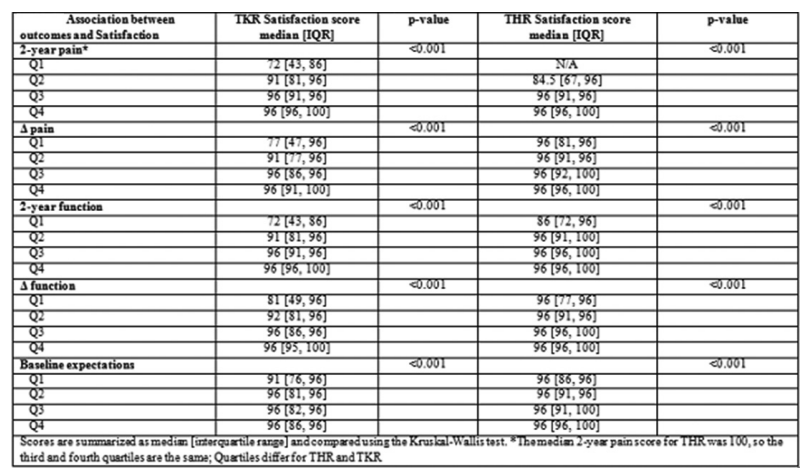

Scores are summarised as median [interquartile range] and compared using the Kruskal-Wallis test. *The median 2 year pain score for THR was 100 , so the third and fourth quartiles are the same; Quartiles differ from THR and TKR

Conclusions: These findings confirm that with increasing relief of pain and functional improvement, the strength of the association of 2 core domains with satisfaction increases, further validating these core domains for use in TJR clinical trials. A core outcome measurement set needs to be defined for use in. TJR clinical trials that includes validated measures of these domains.

Disclosure of Interest: S. Goodman: None declared, B. Mehta: None declared, L. Mandl Grant/research support from: Boehringer-Ingelheim, J. Szymonifka: None declared, M. Figgie Shareholder of: Mekanika, I. Navarro-Millan: None declared, M. Bostrom: None declared, D. Padgett: None declared, A. McLawhorn: None declared, S. Lyman: None declared, J. Singh: None declared DOI: 10.1136/annrheumdis-2018-eular.2555 